\title{
Сергей Лунев
}

Бывший председатель Избирательной комиссии Калининградской области Калининград, Россия

\section{Исторические, правовые и политические аспекты выборов в региональные органы представительной власти Калининградской области Российской Федерации (1993-2013 гг.)}

Резюме: Калининградская область занимает особое место среди других российских регионов как с исторической точки зрения, ввиду присоединения ее к Российской Федерации по итогам Второй мировой войны в 1945 году, так и с географической, как регион, не соединенный с основной территорией России и граничащий только с государствами Евросоюза - Польшей и Литвой. Соответственно, исследование электорального поведения калининградских избирателей на протяжении выборных кампаний 1993-2013 гг. представляет значительный интерес с учетом существенного взаимовлияния и культурно-делового обмена области с соседними европейскими странами.

Следует отметить, что результаты многочисленных выборных кампаний исследуемого периода в целом отражали общероссийские тенденции и закономерности процессов развития избирательной системы, состояния структур гражданского общества и политических партий, а также избирательного законодательства. На этом историческом этапе прослеживается последовательное формирование системы разделения властей на всем пространстве Российской Федерации. При этом динамика российского федерализма не носила однонаправленного характера и не отличалась последовательностью и стабильностью. Значительным и многократным изменениям подвергались выборные процедуры в региональные законодательные собрания, избирательный процесс на выборах губернаторов.

В данной статье приведен анализ проводившихся с 1993 года в регионе избирательных кампаний по выборам депутатов областной Думы и применявшегося законодательства, который позволяет сделать выводы о том, что как в Калининградской области, так и в других субъектах федерации производилось в основном копирование всех элементов избирательной системы, применяемой на выборах депутатов Государственной Думы Федерального Собрания РФ. Унификация избирательного законодательства на всей территории РФ повлекла все большее сходство избирательных систем регионов друг с другом без учета их региональной специфики. Продолжающаяся на федеральном уровне правовая 
трансформация избирательных процедур определяет дальнейший поиск оптимальной выборной модели в РФ.

Ключевые слова: местные выборы, избирательное законодательство, Калининградская область, Россия

\section{Вступление}

$\mathbf{K}$ алининградская область выделяется из числа других российских регионов достаточно неординарной политической историей. Её особенности связаны с периодом становления после Второй мировой войны, когда из состава части территории германской Восточной Пруссии она по итогам потсдамских соглашений 1945 г. перешла под юрисдикцию СССР и заселялась переселенцами в основном из центральных областей России, Белоруссии и Украины, а также и с постсоветским периодом ввиду особой ситуации трансформации в регион, не соединенный с основной территорией России и граничащий с государствами Евросоюза - Польшей и Литвой. Эти особенности, характеризующиеся серьезным взаимовлиянием, интенсивным культурным и деловым обменом области с соседними европейскими странами, существенным образом отражаются на мировоззрении значительной части населения региона и электоральных процессах, происходивших в нем на протяжении прошедших 20 лет.

Наряду с этим, электоральное поведение калининградских избирателей на протяжении многочисленных выборных кампаний 19932013 гг. неизбежно отражало общероссийские тенденции и закономерности процессов развития избирательной системы, состояния структур гражданского общества и политических партий, а также избирательного законодательства.

Региональные изменения политической системы, которые происходили в России с начала 1990-х годов, свидетельствуют об эволюции, которую совершил российский федерализм. На этом историческом этапе прослеживается последовательное формирование системы разделения властей на всем пространстве Российской Федерации, когда в каждой области, крае, республике, крупном городе образовывались не только администрации, но и избирались местные парламенты (законодательные собрания), учреждались конституционные или уставные суды. При этом динамика российского федерализма не носила однонаправленного характера и не отличалась последовательностью и ста- 
бильностью. Периодически изменялись общие принципы организации власти в субъектах Федерации, способы формирования «палаты регионов» Федерального Собрания - Совета Федерации. Существенным и многократным изменениям подверглись выборные процедуры в региональные законодательные собрания, избирательный процесс на выборах губернаторов. При этом региональные выборы отличались значительным своеобразием по сравнению с выборами в федеральные органы государственной власти. Это связано с тем, что каждый элемент регионального избирательного процесса, начиная с правового статуса избирателей и кандидатов на выборные должности и заканчивая процедурами голосования, обладает своей спецификой.

В соответствии с Конституцией России, Федеральным законом «Об основных гарантиях избирательных прав и права на участие в референдуме граждан РФ», конституциями (уставами) субъектов РФ избирательные системы по выборам в региональные органы государственной власти устанавливаются федеральными законами и законами субъектов РФ.

Вопрос о пределах разграничения федеральной и региональных избирательных систем является дискуссионным. При выборах в органы государственной власти субъекты Федерации обязаны соблюдать федеральное законодательство о выборах и в то же время самостоятельно принимать его на своем уровне. Российский политолог М.Баглай правомерно отмечает, что такой подход, с одной стороны, обеспечивает относительное единообразие избирательных систем Федерации и ее субъектов, а с другой - порождает различия в избирательных системах субъектов Федерации (Баглай, 2000, с. 446). Соответственно, не представляется возможным утверждать об избирательной системе в субъектах Федерации как о единой для всех. Более правомерным является утверждение о том, что в Российской Федерации действует только одна федеральная избирательная система, а также избирательные системы субъектов Федерации и органов местного самоуправления соответственно их количеству.

\section{Выборы в региональный орган представительной власти Калининградской области Российской Федерации в период 1993-2013 гг.}

Представительным (законодательным) органом государственной власти в Калининградской области в соответствии с Уставом (Основ- 
ным Законом) области является Калининградская областная Дума. Данный орган власти возник вследствие проведения конституционной реформы после выхода Указа Президента Российской Федерации № 1400 от 21 сентября 1993 г. «О поэтапной конституционной реформе в Российской Федерации». 9 октября 1993 г. Президент России Б. Ельцин издал Указ № 1617 «О реформе органов представительной власти и органов местного самоуправления в Российской Федерации», предписав реформировать органы представительной власти краев, областей, городов федерального значения и органы местного самоуправления.

Было установлено, что в краях, областях и городах федерального значения населением должны быть избраны органы представительной власти (Законодательные Собрания, Думы и т.п.) в составе 15-50 депутатов, работающие на постоянной основе. Предусматривалось, что до избрания и начала работы новых органов представительной власти и местного самоуправления исполнительно-распорядительные функции, закрепленные законодательством Российской Федерации за Советами народных депутатов краев и областей, городов федерального значения, осуществляются администрацией соответствующего субъекта Российской Федерации.

Исполняя эти федеральные нормативные акты, 24 января 1994 г. глава администрации Калининградской области Ю.Маточкин издал постановление № 14, на основании которого полномочия депутатов Калининградского областного Совета народных депутатов считались прекращенными с 27 марта 1994 г., и утвердил «Положение о выборах в областную Думу Калининградской области». Положение предписывало проведение выборов депутатов областной Думы первого созыва 27 марта 1994 г. по мажоритарной системе (первоначально 27 избирательных округов, затем Положение было изменено на 21 одномандатный избирательный округ) со сроком полномочий 2 года. Право выдвижения кандидатов принадлежало региональным группам избирателей и избирательным объединениям, к которым относились «отделения общефедеральных партий, политических движений, иных общественных объединений, устав которых зарегистрирован Министерством юстиции Российской Федерации и предусматривал участие в выборах, региональные партии, политические движения, иные общественные объединения, устав которых зарегистрирован в установленном порядке и предусматривал участие в выборах, блок указанных общественных объединений, создаваемый на период проведения выборов». 
Положение предоставляло право голосования каждому гражданину Российской Федерации, достигшему 18-летнего возраста и постоянно проживающему на территории Калининградской области. Выдвигаться в качестве кандидатов могли лица, достигшие 21 года. Кандидата в депутаты могла выдвинуть группа избирателей, включающая не менее 40 человек (Маслов, Зюбанов, Комаревцев, 2007, с. 161).

Задачи подготовки и проведения выборов в Думу были возложены главой администрации Калининградской области на Окружную избирательную комиссию по выборам в Федеральное Собрание (ныне - Избирательная комиссия Калининградской области). Позднее, 17 апреля 1994 года Калининградская областная Дума первого созыва приняла Закон «О региональной избирательной комиссии Калининградской области». После этого Комиссия приобрела статус юридического лица, на нее возлагались полномочия по проведению на территории области всероссийских референдумов, выборов Президента РФ, выборов в федеральные и региональные органы государственной власти и содействие в проведении выборов в органы местного самоуправления и местных референдумов.

Выборы депутатов Калининградской областной Думы первого созыва состоялись 27 марта 1994 года при невысокой активности избирателей $(35,4 \%)$. Было избрано 20 депутатов, при этом в 21-м округе (Октябрьский район Калининграда) выборы не состоялись, так как количество действительных бюллетеней составило менее $25 \%$ от общего числа избирателей (Общие итоги выборов депутатов Думы Калининградской области, „Калининградская правда”, 1.04.1994).

2 октября 1994 года состоялось голосование на повторных выборах депутата по 21-му округу, однако выборы вновь были признаны несостоявшимися ввиду низкой явки избирателей на участки. При этом необходимо отметить, что трагические события конфликта российской исполнительной и представительной власти на федеральном уровне в 1993 году и судьба ранее действовавших Советов, которые были распущены вышеупомянутым Указом Президента России, существенно негативным образом повлияли на настроения избирателей. Большинство избирателей, видя нестабильную социально-экономическую обстановку и недостаточную законодательную базу, полагало перспективы работы избираемого нового органа представительной власти непредсказуемыми. Лишь 17 декабря 1995 г. (одновременно с выборами депутатов Государственной Думы вто- 
рого созыва) повторные выборы депутата по 21-му округу успешно состоялись.

Следующие выборы депутатов областной Думы (второго созыва) были проведены 6 октября 1996 года. Выборы прошли в соответствии с принятым 31 мая 1996 г. Уставом (Основным Законом) Калининградской области № 50 и Законом Калининградской области от 27 сентября 1995 г. № 22 «О выборах депутатов Калининградской областной Думы» (с поправками 29 февраля 1996 г., 23 мая 1996 г., 27 июня 1996 г.) - по смешанной мажоритарно-пропорциональной системе (27 одномандатных избирательных округов и один общерегиональный избирательный округ по спискам избирательных блоков и объединений - 5 мандатов) со сроком полномочий депутатов 4 года.

В выборах по общерегиональному избирательному округу 6 октября 1996 г. принимали участие два избирательных объединения (Калининградская областная организация Коммунистической партии РФ и Калининградская областная федерация профсоюзов) и два избирательных блока - «Янтарный край России» («Яблоко», «Демократический выбор России» и «Наш дом - Россия») и «Сторонники А. Лебедя, С. Федорова, С. Глазьева - за региональное развитие».

«Янтарный край России» был единым демократическим списком, который поддерживал губернатор Ю. С. Маточкин, проигравший на проходивших одновременно выборах главы региона. Блок «Сторонники А. Лебедя, С. Федорова, С. Глазьева - за региональное развитие» был удачным проектом региональных организаций Конгресса Русских Общин и Демократической партии России. Все четыре списка при общей явке избирателей $45,1 \%$ преодолели $5 \%$-ный барьер, но список профсоюзов в соответствии с методикой распределения депутатских мандатов все равно не получил ни одного места.

Областной закон «О выборах депутатов Калининградской областной Думы» являлся рамочным и в целом повторял формулировки «Положения о выборах в областную Думу Калининградской области» без существенных изменений. В последующем федеральное законодательство о выборах, на которое был ориентирован региональный избирательный закон, претерпело существенные изменения - в 1999 году был принят в новой редакции Федеральный Закон «Об основных гарантиях избирательных прав граждан и права на участие в референдуме граждан». Это потребовало внесения многочисленных поправок (4 октября 1999 г. и 24 мая 2000 г.) в Закон 
Калининградской области «О выборах депутатов Калининградской областной Думы». В результате внесенных поправок региональный Закон впервые был значительно дополнен подробной регламентацией порядка подготовки списков избирателей, описанием статуса, полномочий и порядка формирования избирательных комиссий, порядка выдвижения кандидатов и формирования избирательных блоков, процедуры сбора подписей избирателей в поддержку кандидата, статуса наблюдателей, регистрации кандидатов, порядка и сроков осуществления предвыборной агитации, в том числе в СМИ, финансового обеспечения выборов и отчетности, порядка внесения избирательного залога, подсчета голосов и др.

Выборы депутатов областной Думы третьего созыва были проведены 5 ноября 2000 г. в соответствии с Уставом (Основным Законом) Калининградской области (с поправками от 12 апреля 2000 г.) и Законом Калининградской области от 27 сентября 1995 г. № 22 (с поправками от 24 мая 2000 г. № 209) «О выборах депутатов Калининградской областной Думы», по ранее принятой смешанной избирательной системе (27 одномандатных избирательных округов и общерегиональный избирательный округ по спискам избирательных блоков и объединений - 5 мандатов, срок полномочий 5 лет). Уже 10 сентября 2000 г. почти 200 человек уведомили Избирательную комиссию области о желании баллотироваться в Калининградскую областную Думу по одномандатным округам и около 100 человек - по партийным спискам. Для сравнения - на первых выборах 1994 г. выдвигались по одномандатным округам 85 кандидатов, то есть был отмечен более чем двукратный рост числа граждан, намеревавшихся воспользоваться своим пассивным избирательным правом.

5 ноября 2000 г. на выборах в областную Думу из 32-х утвержденных округов выборы состоялись в 26-ти округах. Знаменательно, что в 6-ти округах выборы были признаны несостоявшимися, поскольку против всех кандидатов проголосовало большее количество избирателей, чем за кого-либо из них. При этом всего по имеющейся в бюллетене графе «против всех» проголосовали более 63 тыс. человек, или 20\% избирателей (Маслов, Зюбанов, Комаревцев, 2007, с. 164).

Статистика подтверждает, что такого количества голосовавших «против всех» не было ни до, ни после этих выборов, что свидетельствует о высокой на тот момент степени разочарования как в самих кандидатах и действовавших политических партиях, так и в результатах их предшествующей деятельности (последствия тяжелого эконо- 
мического кризиса 1998 года, фрагментарность и персонализованная ориентированность политических партий и т.д.). Избиратели стремились через процедуру голосования выразить свой протест против сложной экономической ситуации, сложившейся на некоторых территориях области после известных событий дефолта 1998 года.

В Черняховском районе, например, по мажоритарному округу не был избран депутат областной Думы, так как избиратели предпочли проголосовать «против всех». По партийным спискам в этом районе преимущественным было также голосование «против всех». В то же время, необходимо отметить, что на выборах 2000 г. первое место в регионе занял список избирательного блока «В поддержку Президента России», созданный фактически теми же силами, что и блок сторонников Лебедя, Федорова и Глазьева в 1996 году. Его лидер Б. Шушкин, до этого в 1996 г. успешно проведший кампанию от имени названного блока, вновь удачно использовал политическую конъюнктуру, хотя реально данный блок никакого отношения к Президенту России В. Путину вообще не имел. Его образовали региональные организации Демократической партии России, Конгресса Русских Общин и областное Экологическое общественно-политическое движение. Вместе с тем, этот блок эффективно использовал в своих целях большие надежды на позитивные изменения в стране, которые связывались избирателями в 2000-м году с молодым и энергичным лидером В. Путиным, активно начавшим в тот период проведение реформ в экономике. Действовавшее на тот момент законодательство разрешало ситуацию, когда при создании избирательных блоков и в ходе предвыборной агитации допускалось использование имени политического лидера без его согласия.

Второе место занял список Коммунистической партии РФ (КПРФ), третье - «ЯБЛОКО - Новая сила» (блок регионального «Яблока» и Союза правых сил, ранее участники этого блока входили в «Янтарный край России»). В проправительственном блоке «Янтарный край России», занявшем только 4-е место, в 2000-м году оставались только политические партии «Демократический выбор России» и Республиканская партия Российской Федерации. Этот избирательный блок выступал в пользу адмирала В. Егорова, который победил на проходивших одновременно губернаторских выборах. Еще одно депутатское место получил представитель Калининградского регионального отделения ЛДПР, которая преодолела на выборах пятипроцентный барьер (Маслов, Зюбанов, Комаревцев, 2007, с. 164). 
Потерпел провал список сторонников блока действовавшего губернатора области Л. Горбенко «Запад России», который был создан из региональных организаций партий «Наш дом - Россия», «Женщины России» и др. Минимальный результат получили списки «Отечества», Аграрной партии России, «Союза труда». Не имела успеха и сугубо региональная политическая организация - Балтийская республиканская партия во главе с президентом Калининградского союза предпринимателей С. Пасько, выступающая за предоставление Калининградской области статуса республики в составе Российской Федерации и предоставление области больших политических и экономических прав.

На выборах депутатов Калининградской областной Думы и в 1996, и в 2000 г.г. применялась одинаковая избирательная система, по которой 27 депутатов избирались по одномандатным округам и только 5 - по партийным спискам.

Следует отметить, что 4 марта 2001 г. состоялись дополнительные выборы в Калининградскую областную Думу по избирательным округам, где ранее выборы были признаны несостоявшимися. Интересно, что в округе № 14 победила исполнительный директор фонда обязательного медицинского страхования Е. Клюйкова, а бывший губернатор области Л. Горбенко, баллотировавшийся по этому же округу, занял лишь четвертое место. В общей сложности на вакантные семь мест в областной Думе претендовал 61 кандидат.

Анализ результатов выборов рассматриваемого периода свидетельствует, что они отражали реальное соотношение сил в ходе голосования, что косвенно подтверждается крайне низкими результатами выборов в отношении обладавшего значительным административным ресурсом действующего непопулярного губернатора Л. Горбенко или проправительственных избирательных объединений. Однако в то же время явно просматривалась неструктурированность политических партий и движений, а кажущееся многообразие участников региональной политической жизни на деле выявляло ограниченность их реальной роли и политических функций. Способности политических партий выражать интересы гражданского общества являлись весьма условными, поскольку интересы гражданского общества только начинали формироваться, а сами партии практически никого не представляли, кроме их лидеров и ближайших сторонников. Партии, движения и избирательные блоки того периода объединяли совершенно незначительную часть единомышленников вокруг како- 
го-либо известного на федеральном уровне политического деятеля, не отражая какой-либо связи власти с гражданским обществом.

Кроме того, влияние исполнительной власти региона на электоральные процессы было минимальным: использование административного ресурса и «чёрных» технологий, которое позднее приобрело выраженный характер, на данном этапе практически отсутствовало. Несмотря на все издержки, выборы проходили в форме конкуренции идей и не носили характера хорошо отрежиссированного спектакля с заранее известным финалом. Принадлежность к «партии власти» (КПСС в 1990-м или в последующем «Выбор России» или «Наш дом-Россия») не только не была гарантированным «пропуском на депутатские места», но и создавала ряд проблем, в связи с чем некоторые соискатели депутатских мандатов старались вообще не афишировать свою партийную принадлежность.

В последующем предпринятые федеральным центром меры позволили значительно изменить ситуацию с формированием политических партий и участием в выборах избирательных объединений. Новый этап был обусловлен принятием в июле 2001 года Федерального закона «О политических партиях». В результате в избирательное законодательство, в частности, в Федеральный закон «Об основных гарантиях...», в 2002 году были внесены некоторые важные изменения: на федеральных и региональных выборах избирательными объединениями признавались только политические партии и их региональные объединения, на муниципальных - и иные общественные объединения. Было изменено понятие избирательного блока (а в последующем он был вообще отменен), вводилась смешанная избирательная система на выборах депутатов региональных парламентов, а также предусматривалось уточнение порядка формирования избирательных комиссий (1\2 состава комиссии обязательно формируется по представлению входящих в состав действующей Государственной Думы политических партий). Результатом этих нововведений стало постепенное появление более структурированной партийной системы, которая сложилась в ходе последующих федеральных и региональных выборов, а также существенных изменений избирательного и смежного с ним законодательства. При постоянной ведущей роли объединенной центристской «Единой России», за которую в последующем традиционно голосовало большинство избирателей и которую стал называть «партией власти», в дальнейшем как в Государственную Думу, так и в представительные собрания регионов 
по спискам избирательных объединений стали избираться, за очень редким исключением, представители только трех других партий: КПРФ, ЛДПР и созданной позднее «Справедливой России».

В соответствии с подписанным Президентом РФ 21 июля 2005 г. Федеральным законом, Калининградская областная дума 2 августа 2005 г. приняла региональный Закон о новых выборах депутатов в марте 2006 г., при этом были внесены изменения в Устав (Основной закон) Калининградской области. В соответствии с этими поправками Калининградская областная Дума стала формироваться следующим образом: 20 депутатов избирались по мажоритарной, 20 - по пропорциональной системе по спискам региональных отделений политических партий. Областной закон установил 7-процентный барьер, преодолев который, зарегистрированный облизбиркомом список регионального отделения политической партии допускался к распределению депутатских мандатов.

12 марта 2006 года были проведены выборы депутатов областной Думы четвертого созыва. Устав (Основной Закон) Калининградской области в редакции от 31 марта 2005 г. установил новую численность Калининградской областной Думы - 40 депутатов, а Закон Калининградской области от 8 июля 2003 г. № 286 «О выборах депутатов Калининградской областной Думы» предусмотрел избрание 20 депутатов по мажоритарной системе - по одномандатным и многомандатным избирательным округам, и 20 депутатов по пропорциональной системе - по единому общерегиональному избирательному округу по спискам региональных отделений политических партий. Областной закон также сохранил 7\% барьер для партий, список которых был зарегистрирован Избирательной комиссией Калининградской области.

Результаты выборов в целом отражали ситуацию с предпочтениями избирателей на общефедеральном уровне. При участии в голосовании 257776 избирателей из зарегистрированных 740363 досрочно проголосовали 10 585, в избирательный бюллетень было включено 7 политических партий из 12-ти, намеревавшихся принять участие в выборах. Остальные партии по различным причинам не смогли участвовать. По единому общерегиональному избирательному округу по спискам региональных отделений политических партий «Единая Россия» набрала 34,12\% голосов, КПРФ - 15,09\%, ЛДПР - 7,53\%, а существовавшая в тот период «Российская партия пенсионеров» $-8,91 \%$. 
Следующие выборы в областную Думу пятого созыва состоялись 13 марта 2011 года. Требования областного законодательства о порядке формирования регионального представительного органа вновь были изменены в части создания избирательных округов: 20 депутатов только по одномандатным избирательным округам и 20 - о единому избирательному округу в составе списков избирательных объединений. Данные условия были приняты на основании статьи 4 Уставного Закона Калининградской области «О выборах депутатов Калининградской областной Думы» от 29 сентября 2010 г. № 497 (с поправками от 24 ноября 2010 г. и 5 марта 2011 г.). Порядок распределения депутатских мандатов по результатам голосования был установлен в соответствии с системой Империали. Вначале в соответствии со статьей 84 названного регионального Уставного закона, каждому списку кандидатов, получившему менее 7 , но не менее 5 процентов голосов избирателей, принявших участие в голосовании, и не допущенному к распределению депутатских мандатов, должен был передаваться один депутатский мандат. Таковых по результатам голосования 13 марта 2011 г. не оказалось.

Затем каждый список кандидатов по единому избирательному округу, допущенный к распределению депутатских мандатов, должен был получить по одному мандату из числа мандатов, оставшихся после передачи мандатов в соответствии со статьей 84 Уставного закона, после чего проводилось распределение оставшихся депутатских мандатов в следующем порядке (статья 85 Уставного закона): сумма голосов избирателей, полученных каждым списком кандидатов по единому избирательному округу, допущенным к распределению депутатских мандатов, последовательно делится на числа из ряда возрастающих натуральных чисел (делителей) начиная с двуx до числа оставшихся депутатских мандатов, распределяемых по единому избирательному округу (Уставный Закон Калининградской области «О выборах депутатов Калининградской областной Думы» от 29 сентября 2010 г. № 497).

В голосовании 13 марта 2011 г. приняло участие 330195 избирателей из 763511 избирателей, включенных в избирательные списки на территории всей Калининградской области, или 43,25\% от общего числа избирателей. При этом досрочно проголосовали только 3289 избирателей, то есть процент досрочного голосования являлся весьма низким, в то время как общее число открепительных удостоверений, изготовленных для досрочного голосования, составляло 12000. 
Было избрано 40 депутатов со сроком полномочий 5 лет. Из них 20 депутатов были избраны по единому избирательному округу: «Единая Россия» получила 9 депутатских мест (за нее проголосовал 134651 избиратель, или 41,48\%), КПРФ - 5 мандатов (70 675 - 21,02\%), «Патриоты России», «Справедливая Россия» и ЛДПР получили по 2 мандата (за них проголосовали соответственно 28046 - 8,19\%, 33333 - 10,16\% и 41534 - 12,60\% избирателей). Также участвовавшая в выборах партия «Яблоко» получила только 2,35\% голосов и не участвовала в распределении мест. Кроме того, 20 депутатов были избраны по одномандатным мажоритарным округам.

\section{Выводы}

Анализ всех проводившихся с 1993 г. в регионе избирательных кампаний по выборам депутатов областной Думы и применяемого законодательства свидетельствует о том, что отмечалась постоянная тенденция копирования на уровне субъекта федерации основных элементов избирательной системы, применяемой на выборах депутатов Государственной Думы Федерального Собрания РФ. При этом Калининградская область не является исключением, а избирательные системы в различных субъектах РФ приобретают все большее сходство друг с другом, становятся более унифицированными, без учета региональной специфики. С каждым электоральным циклом проводилась работа по обобщению опыта избирательных кампаний в субъектах РФ, поиску оптимальной выборной модели. Однако постоянное реформирование федерального избирательного законодательства и усиление его роли препятствовало становлению избирательного законодательства в субъектах РФ, в связи с чем практически каждый из электоральных этапов характеризовался иным состоянием законодательного обеспечения выборов.

Поэтому крайне редко избирательные кампании по выборам органов государственной власти в области проводились по тем же правилам, что и предыдущие, в связи с чем процесс становления региональной избирательной системы до сих пор нельзя назвать окончательно завершенным.

В настоящее время региональная пропорциональная система в целом получила свое организационно-правовое выражение и относительное количественное доминирование над избирательны- 
ми системами, основанными на принципе большинства, тогда как в 90-х годах предпочтение отдавалось мажоритарной избирательной системе. Это объясняется тем, что введение пропорциональной составляющей в качестве обязательного элемента избирательных систем в субъектах РФ связывалось со стимулированием деятельности общероссийских политических партий в регионах и их участием в региональных выборах, что и было достигнуто.

В настоящее время заведомо высокий заградительный барьер 7\% и введенный в региональное избирательное законодательство «метод Империале» для распределения голосов, преследующий цель усилить позиции крупных политический партий, снижают представительность областного парламента и не вполне согласуются с принципами политического и идеологического многообразия, приоритета народовластия.

Следует особо отметить, что в Федеральный Закон РФ «О выборах депутатов Государственной Думы Федерального Собрания РФ» от 22.02.2014 г. (статья 88, пункты 7 и 8) 24 ноября 2014 г. были внесены поправки, вернувшие на федеральном уровне выборов в Государственную Думу для политических партий 5\%-ный «заградительный» барьер без каких-либо ограничений и соответственно отменившие $7 \%$.

Однако Уставным законом Калининградской области от 06.10.2014 г. № 347 статья 84 Уставного Закона области «О выборах депутатов Калининградской областной Думы», регулирующая порядок передачи депутатских мандатов по результатам выборов, признана действующей до 6 мая 2018 года. Тем самым остался сохраненным на следующий электоральный цикл в 2016 году общий 7\%-ный порог при пропорциональной системе проведения выборов, и политические партии, получившие более 5, но менее 7 процентов голосов избирателей, вопреки федеральной тенденции смогут получить только по одному депутатскому мандату.

В целом же принцип главенства федерального законодательства над региональным предопределяет продолжающуюся унификацию положений выборных законов в ущерб принципам федерализма. Эта унификация в большинстве случаев порождает практически зеркальное отражение на региональном уровне федеральную картину основных результатов выборов. Отсюда степень влияния применяемой избирательной системы на политическую ситуацию в регионе прогнозируется с высокой вероятностью и не может принципиально отличаться от федеральной, при условии, что в предшествующий вы- 
борам период по каким-либо объективным или субъективным причинам в регионе не происходит значимых локальных экономических или социально-политических событий или изменений, существенно затрагивающих интересы большого числа избирателей.

В настоящее время в России малореальной представляется возможность создания и функционирования хорошо работающей избирательной системы до тех пор, пока в обществе не будут сформированы и усвоены основными политическими элитами консенсусные представления об основных направлениях национально-государственного строительства.

Особенностью политического процесса в России является активный политический стиль, состоящий в навязывании обществу нововведений со стороны центральной власти. Активная роль государства в интеграции интересов различных групп вызвана культурно-религиозной, этнической и политической неоднородностью общества. Эту интеграцию различных субкультур участников политического процесса государство проводило методом навязывания им определенных ценностей и стандартов политической деятельности. Тем самым властные структуры делали поведение субъектов политики более предсказуемым. При очень низком уровне самоорганизации политической жизни общества, особенно в регионах, такое влияние представляется вполне оправданным, однако при обязательном условии, чтобы основной его вектор был направлен в сторону демократизации жизни и деятельности всех политических и общественных структур.

Для сбалансированного и обоснованного совершенствования регионального законодательства на настоящем этапе представляется целесообразным вопрос о реформе избирательной системы, используемой при формировании представительного органа государственной власти Калининградской области, решать только через областной референдум населением региона - народом как носителем власти, в соответствии с положениями Конституции России.

\section{Заключение}

Актуальность темы данной статьи обусловлена тем, что в условиях развития всех государственных институтов Российской Федерации в период 1993-2013 гг. постоянной трансформации подвергалась российская избирательная система, в том числе на ее региональном 
уровне. В целях следования конституционным принципам Российской Федерации и международным демократическим избирательным стандартам в области построения региональных избирательных систем, повышенного внимания требует всесторонний анализ развития регионального российского избирательного и смежного с ним законодательства, оказывающего существенное влияние на становление избирательных систем в субъектах Федерации. Многие современные проблемы в сфере определения и законодательного закрепления конкретного вида избирательной системы либо отдельных ее элементов, используемых для выборов в органы государственной власти субъектов Федерации, связаны с постоянным реформированием федерального избирательного законодательства. В связи с этим диапазон регионального правотворчества в данной сфере значительно сужается и продолжается процесс унификации избирательного законодательства на всей территории РФ без учета региональной специфики.

\section{Библиография}

\section{Книги и статьи:}

Баглай М. (2000), Конституционное право Российской Федерации, Москва. Бешлер Ж. (1994), Демократия, Москва.

Иванченко А., Кынев А., Любарев А. (2005), Пропорииональная избирательная система в России. История, современное состояние, перспективы, Москва.

Маслов В., Зюбанов В., Комаревцев Б. (2007), История выборов в Калининградской области (1946-2006), Избирательная комиссия Калининградской области, Калининград.

Общие итоги выборов депутатов Думы Калининградской области, „Калининградская правда", 01.04.1994.

Butler D. E., Penniman H., Ranney A. (1981), Democracy at the Polls. A Comparative Study of Competitive Elections, Washington.

Easton D. (1965), A System Analysis of Political Life, John Wiley Inc., New York.

LijphartA. (1984),Democracies: Patterns of Majoritarian and Consensus Government in Twenty-One Countries, Yale University Press, New Haven.

Lipset S. M. (1991), No Third Way: A Comparative Perspective on the Left, in: The Crisis of Leninism and the Decline of the Left: The Revolutions of 1989, ed. D. Chirot, University of Washington Press, Seattle.

Skotnicki K. (2010), Funkcje wyborów a wielkość okręgów wyborczych, Toruń.

Żukowski A. (2010), System wyborczy III RP - refleksja i postulaty zmian, w: 
Rzeczpospolita Polska 1989-2009. Problemy wybrane, red. K. Leszczyńska, Torun.

\section{Документы:}

Федеральный закон «Об основных гарантиях избирательных прав и права на участие в референдуме граждан РФ» от 12.06.2002 г. № 67 (в редакции от 03.11.2015 г.).

Федеральный Закон РФ «О выборах депутатов Государственной Думы Федерального Собрания РФ» от 22.02.2014 г. (в редакции от 24.11.2014 г.).

Конституция Российской Федерации.

Указ Президента Российской Федерации № 1400 от 21 сентября 1993 г. «О поэтапной конституционной реформе в Российской Федерации».

Указ Президента Российской Федерации № 1617 от 9 октября 1993 г. «О реформе органов представительной власти и органов местного самоуправления в Российской Федерации».

Уставный Закон Калининградской области «О выборах депутатов Калининградской областной Думы» от 29 сентября 2010 года № 497 (в редакции от 06.10.2014 г.).

Устав (Основной Закон) Калининградской области № 50 от 31 мая 1996 г.

Закон Калининградской области от 27 сентября 1995 г. № 22 «О выборах депутатов Калининградской областной Думьл».

Постановление главы администраџии Калининградской области от 24 января 1994 г. № 14 «Об утверждении Положения о выборах в областную Думу Калининградской области».

\section{Ресурсы Интернета:}

Центральная избирательная комиссия Российской Федерации, http://www.cikrf.ru. Избирательная комиссия Калининградской области, http://www.izbirkom39.ru.

Газета „Калининградская правда”, http:/www.kaliningradka.ru.

Независимые общественные интернет-ресурсы: http://www.newkaliningrad.ru и http://www.rugrad.eu.

Historical, judicial and political aspects of elections to the bodies of regional authorities in the Kaliningrad Region of the Russian Federation in the years 1993-2013

\section{Summary}

This paper analyzes the regional elections of the deputies to the Kaliningrad Oblast Duma, starting in 1993 and the applicable legislation, and leads to the conclusion that, in general, all the elements of the election system of deputies of the State Duma, 
or the Federal Assembly of the Russian Federation, are replicated in the Kaliningrad region and other units of the Federation. The unification of the electoral legislation across the entire Russian Federation promoted greater similarity of the election systems of different regions, without taking into account their specific character. The transformation of the law on electoral procedures on the federal level, which is still in progress, determines further search for an optimal election model in the Russian Federation.

Key words: local elections, electoral law, Kaliningrad Region, Russia

\section{Historyczne, prawne i polityczne aspekty wyborów do lokalnych organów władzy w Obwodzie Kaliningradzkim Federacji Rosyjskiej w latach 1993-2013}

\section{Streszczenie}

W artykule dokonano analizy regionalnych wyborów przedstawicieli do Dumy Obwodu Kaliningradzkiego począwszy od roku 1993 i obowiązujących regulacji prawnych, co pozwoliło stwierdzić, że - ogólnie rzecz biorąc - wszystkie elementy systemu wyborczego przedstawicieli Dumy Państwowej, zwanej inaczej Zgromadzeniem Narodowym Federacji Rosyjskiej, są powielane w Obwodzie Kaliningradzkim i innych częściach Federacji. Ujednolicenie przepisów wyborczych na obszarze całej Federacji Rosyjskiej sprzyjało większemu upodobnieniu systemów wyborczych obowiązujących w różnych regionach bez uwzględniania ich odmiennego charakteru. Będąca w toku ewolucja procedur wyborczych na poziomie federalnym zmierza w kierunku poszukiwań modelu wyborczego, który okaże się optymalny dla Federacji Rosyjskiej.

Słowa kluczowe: wybory lokalne, prawo wyborcze, Obwód Kaliningradzki, Rosja 